\title{
MERGERS AND CHANGE MANAGEMENT AT THE MICRO LEVEL: A CASE STUDY
}

\author{
WENDY R KILFOIL \\ kilfowr@unisa.ac.za \\ Institute for Curriculum and Learning Development \\ University of South Africa \\ THOMAS GROENEWALD \\ tgroenew@unisa.ac.za \\ Directorate Tutorial Services \& Work-integrated Learning \\ University of South Africa
}

\begin{abstract}
The transformation of the South African higher education landscape resulted in, among other things, the merger of three distance education institutions: Unisa, VUDEC and TSA. The macro level of the merger will no doubt be studied in detail. This article explores a micro level process for two departments merged by a top-down decision that did not take cognisance of their dissimilar functions and structures. The result was both a merger and a demerging process. The two departments first had to confront the realities of their different functions and structures before a reconfiguration could occur, including the emergence of a strategic plan focusing on aspects such as specific contribution, drivers, objectives and structure. The change management principles adopted to ensure the success of the process are outlined, analysed and reflected upon.
\end{abstract}

\section{OPSOMMING}

Die gedaanteverandering van die hoëropvoedkundigelandskap in Suid-Afrika het, onder andere, die samesmelting van drie afstandsonderriginstansies, naamlik Unisa, VUDEC en TSA tot gevolg gehad. Die makrovlak van die samesmelting word uiteraard noukeurig bestudeer. Hierdie artikel ondersoek egter hoofsaaklik die mikrovlakproses vir twee departemente wat op grond van 'n besluit wat van bo afgedwing is, met mekaar moes saamsmelt, sonder enige inagname van hul ongelyksoortige funksies en strukture. Die resultaat was een van beide samesmelting en 'n proses van ontbinding. Die twee departemente moes eers hul onderskeie realiteite van uiteenlopende funksies en strukture konfronteer, alvorens herstrukturering kon plaasvind om uiteindelik 'n strategiese plan daar te stel wat op unieke bydrae, dryfvere, doelwitte en strukture fokus. Die veranderingsbestuursbeginsels wat ingespan is om die sukses van die proses te verseker, word uiteengesit, ondersoek en oor gereflekteer.

\section{MERGERS AND HIGHER EDUCATION}

Mergers have become an established part of life, particularly in the corporate environment (Brousseau, 1989). 'Mergers - the Cisco system' (2002, p. 25) reports that in the year 2002 there were 4363 mergers and acquisitions in the United States of America. However, mergers are not unknown in higher education. In Australia, for instance, many of their current public institutions are the result of a long history of mergers; for example, Deakin University was the result of a number of mergers of technical institutions and teacher education colleges and now offers a wide range of professional, business and industry qualifications and research across five campuses (Hay et al., 2002). This article describes the merger between the University of South Africa (Unisa), Technikon South Africa (TSA) and the distance education campus of Vista University (Vudec) as a background to a discussion of the merger between two departments from the former Unisa and TSA: the Bureau for Learning Development (BLD) and the Centre for Courseware Design and Development (CCDD) respectively. The unit of analysis is therefore the merged department not the whole university. The purpose of documenting the merger is to describe and analyse a real life context in which change interventions occurred, the interventions themselves and their impact. The study is thus primarily descriptive in nature.

The issue to be addressed was the need for deliberate change management in a merger situation. Change management could have a significant impact on staff morale - positive or negative - and affect the pace and success of the merger. The central questions were: What impact would the implementation of change management principles and practices have? How could it help to meet current demands while preparing for long term strategic goals - the university's and the department's? The methodology used change management approaches in

Requests for copies should be addressed to: T Groenewald, TGroenew@unisa.ac.za previously documented theory as the basis for constructing some generic principles. This process was initiated by the director of the merged department. The success of the implementation was later tested using an evaluation instrument to assess the performance of the director. In addition, focus group interviews were used to explore the success of the communication strategies. Several propositions underpinned the change management strategy. The first proposition was that relationship building and participation would lead to greater buy-in and facilitate the merger by building trust. A second was that effective communication was essential. A third was that effective, inclusive planning would help people to reconceptualize their roles in the department and speed up the merger.

The evidence sources used were university merger documentation, documents produced by the merged department that is the focus of this article - the Institute for Curriculum and Learning Development (ICLD) - (the Way forward research document, the strategic plan, the key performance areas), the results of a questionnaire evaluating the director of the ICLD at the end of 2004, focus group interviews in the department in mid-2005 and participant observation.

Impetus for institutional mergers

Clearly one would like to be able to say that the mergers between technikons and universities were the result of educational imperatives but that does not appear to have been the case. In the South African context a political decision was made to alter the higher education landscape. The National Plan for Higher Education (South Africa, 2001, p. 75) states that "the purpose may be that of overcoming the racial fragmentation of the higher education system". In respect of distance education, the motivation was to create 'a single dedicated distance education institution' able to maximize 'economies of scale and scope' and take advantage 'of the rapid changes in information and communications technology'. 
Once the decision had been made, preparation and implementation were left to the various merging partners and it has proved a complex task. Duck (2001) makes two important points about mergers that do not emerge clearly from the way the merger proceeded at the dedicated distance education institution:

- For a change inititative to succeed, the emotional and behavioral aspects must be addressed as thoroughly as the operational issues (xii).

- Change unfolds in a reasonably predictable and manageable series of dynamic phases, known as the Change Curve (xii).

Mergers are characterized by heightened emotions, fears of losing one's job, having to move sites, changes to conditions of service that might be unfavourable and so on. Attention to human issues, good communication and speedy resolution of issues can reduce the stress. In this article an attempt by the director of two merged departments from the former Unisa and TSA to address the softer issues in contrast to the institution's focus on operational and structural issues is detailed. The activities described in the article are placed along the Change Curve although the change is far from reaching 'fruition'. Duck labels the Change Curve phases as 'Stagnation, Preparation, Implementation, Determination, and Fruition' (2001, p. 9).

\section{Preparation for merging}

Once the decision was made, the top management members of the institutions were most involved with the preparation phase, a typical pattern. In the Unisa-TSA-Vudec merger, after some initial opposition - including legal proceedings against the Minister of Education - top management members and Councils began to communicate, negotiate and plan. There was a ministerial injunction that it was a merger of equals but Unisa was actually five times the size of TSA and twenty times larger than Vudec in terms of student numbers. A poll of staff members at the three institutions resulted in the new university retaining the name of the University of South Africa although the new institution was to be re-branded. The main impact of the preparation phase for the majority of staff was at an operational level with a freezing of projects, appointments, etc. until after the merger, which caused understandable frustration.

It is essential that leaders collect accurate information and share it with all stakeholders as the basis for facing facts and getting people to change. Much of the pre-merger preparation in 2003 focused on stocktaking of the 'as is' situation in the three institutions although the resulting data was not widely shared in the institution, which led to rumours, an 'us' and 'them' culture and a general climate of mistrust. Considerable work was done in this phase but it will not be detailed here as it is not the focus of the article.

\section{Implementation at macro level: 3 to one}

On 1 January 2004 Unisa merged with TSA to form the new comprehensive University of South Africa. On 2 January the new institution incorporated VUDEC. During 2004 the billboard slogans on the campuses read: ' 3 to one, the countdown has begun to comprehensive distance education for the nation'. Duck makes an interesting remark about the nature of the implementation phase: 'Everything has changed, but nothing has really changed - yet' (2001, p. 26). This was certainly the perception in early 2004 and possibly it remains a reality for some people as change happens at different rates for different people. It was after January 2004 that the focus expanded from the macro to the micro level and the majority of individual departments at the new institution started to be intensively involved in the merger. A number of cross-functional task teams were also established to harmonize policies and focus on the core business of the new comprehensive university. Unisa's management estimated that it would take three years to fully implement the merger. The launch of the new branding identity took place on 30 March 2005, fifteen months after the legal merger.

Marshall (1999, p. 13) suggests that: 'If people are aligned in a common strategic direction and trust each other's motives, then all will move faster'. It was difficult in the first half of 2004 to align all people and departments with a strategic vision and mission as the university's 2004 Business Plan had only an interim vision and mission, and the branding was also interim. The vision and mission - entitled Unisa 2015: An Agenda for Transformation - was finalized in August 2004. Trust takes time to build and a great deal of communication and interaction towards a common goal. The geographical distances separating the main Pretoria and Florida campuses, as well as the even greater distances separating the regions from the main campuses, made personal interaction difficult.

As Duck points out (2001, p. 156), 'In mergers, scale and complexity are the dominant factors'. When an institution is involved in massive, system-wide change, it does not allow for a quick win; when one needs to integrate the whole system, one does not always have the freedom to focus on the greatest need. Systems integration has proved a real problem in the new Unisa because of the physical location of the main campuses and its regional offices as well as the types of technology chosen by the three institutions originally. The ways of dividing and grouping functional areas in the different institutions made one-to-one mergers between departments almost impossible and people clung to turf. Underlying all the structural and procedural issues was the human factor and elements such as entrenched interests or conflict of interests; fear of change or comfort zone and welllearned skills; perceptions of unfairness; fear of losing benefits of current position; additional responsibility and more time and energy needed; possible retrenchment; tools needed to accomplish change not provided.

Two-way communication is important in all phases and the scope of communication must be proportional to extent of the change. In the case of the merger of Unisa, TSA and VUDEC the change was huge. The joint institution had nearly 5000 employees and in 2004 the enrolment exceeded a quarter of a million students. Pollack (2003) recommends a communication plan that shows what information is needed and/or should be shared in each phase and through what methods/media. A merger brings increased workload, executives are busier than ever, they have less time to communicate, but it is more important than ever that they do so. One has to conclude that the new management had no communications plan, based on perceptions of poor performance in this area.

\section{IMPLEMENTATION AT MICRO LEVEI}

The rest of the article deals with the merger of the two departments - the Bureau for Learning Development (BLD) and the Centre for Courseware Design and Development (CCDD) into the Institute for Curriculum and Learning Development (ICLD). The structures and functions of the two departments did not overlap, except in one area: instructional design. The BLD was a professional support department whose staff were education specialists. They worked with lecturers to develop curricula and then learning experiences and environments that enabled students to engage with the content and construct a sound knowledge of the discipline. In addition, the BLD staff members conducted continuing professional learning sessions with groups of academics on topics such as assessment or writing for open distance learning (ODL). They also conducted joint research with lecturers. The CCDD was a cost centre run strictly on project management principles. It included instructional designers - whose work overlapped to some extent with the design function of the learning developers, editors, graphic designers, pre-press staff such as electronic 
originators, project managers and coordinators, a marketing officer, a financial officer and some publishing information technology (IT) support staff. Processes were largely standardized and documented. The CCDD had a limited number of internal clients - because lecturers were not compelled to use their services, since they charged marketrelated prices - and some outside clients. Besides the instructional design, the other functions in the CCDD were performed by separate departments at the Pretoria campus, such as Editorial and Unisa Press.

BLD and CCDD were placed in the Learner Support portfolio of the new comprehensive Unisa although, in fact, they worked with lecturers not students. The Vice Principal: Learner Support asked each of the six departments in his portfolio to prepare a research document for presentation to a Restructuring Committee. Departments that were meant to merge had been holding discussions for some time and most could present a joint research document. BLD and CCDD had had little contact prior to January 2004 or since and had certainly not engaged in an analysis of their respective functions or in joint planning. The result was that the two departments submitted separate research documents. Certain perceived weaknesses and threats were stressed in the BLD research presentation to the Restructuring Committee in March 2004 and carried over into the Way Forward document in May 2004. The BLD document indicated in its SWOT analysis that the merger and the way it was being handled constituted a major threat for the following reasons:

- No principles were established in advance.

- Top down decision-making was not informed by a deep understanding of open and distance learning (ODL).

- There was no communication from top management.

- The misalignment between BLD and CCDD philosophically, functionally and structurally did not make for a successful merger.

- Allocating BLD to the Learner Support Portfolio cut the Bureau off from information from the Academic portfolio, and lecturers are the Bureau's main client.

As part of the merger process, a placement exercise was established to determine which of the two heads of merging departments should be appointed as interim head of department. Only after the director of BLD was made interim head of the joint department in May 2004 did the management committee members of each department get together to start discussing the way forward. This happened at a breakaway session arranged by the Vice Principal for all the departments in his portfolio at an off-campus venue in an attempt to accelerate the merger process.

Collins (2001, p. 65) entitles one of his chapters in Good to great: 'Confront the brutal facts'. Duck (2001, p. 57) talks about 'helping people see the truth' because it makes it easier 'to mobilize them in the cause of change'. The combined BLD-CCDD was starting from behind the other departments at the breakaway and spent the best part of two days just laying their cards on the table, describing processes, sharing job descriptions, etc. It seemed impossible that they could, by the third morning, complete the Way Forward document required by the Vice Principal. On the second day they broke into groups to discuss three scenarios: the Fox scenario, the Hedgehog scenario and the Mouse scenario. The first two were based on a statement in Collins $(2001$, p. 90) related to a parable: 'The fox knows many things, but the hedgehog knows one big thing'. In other words, the one group had to consider the value of remaining a multi-functional department such as the CCDD (the fox) and the other had to consider the advantages and disadvantages of focusing on curriculum and learning development only (the hedgehog). The Mouse scenario was a non-starter so it will not be discussed. The Fox and Hedgehog groups presented their ideas passionately. However, another truth had to be faced: BLD-
CCDD could not compete with the big Editorial and Production departments on the Pretoria campus for mainstream study materials production. They would be engaged in a competitive situation that would probably result in a win-lose situation and endanger jobs. The solution was to split the CCDD into functional units and merge them with existing bigger departments so that structure followed function. The instructional designers would merge with BLD as would the project managers and coordinators. Based on this consensus, they managed to complete most of the document required by the Vice Principal, except for the detailed strategic planning information such as vision, mission, goals, and actions.

\section{Principles to guide the way forward}

One of the items of the Vice Principal's research and planning agenda document required detail on procedures for change management. It was impossible, in March 2004, to put down concrete actions when BLD had not even had a single meeting with their counterparts, CCDD. Instead, the director of BLD drew up the generic guidelines presented in Table 1 below.

\section{TABLE 1}

\section{GENERIC CHANGE MANAGEMENT PRINCIPLES}

Put principles, people and culture first; structures last:

- Build a shared philosophy.

- Be inclusive:

- Adopt a participative approach to decision-making

- Practise relationship-based approaches.

- Deal with affective issues:

- Nurture employees as the valuable intellectual asset and source of strength that they are.

- Actively involve people to the extent possible.

- Build consensus.

- Avoid creating 'losers' from the change; work for win-win.

- Offer choices wherever possible to combat anxiety.

- Create capacity:

- Schedule time and work through the process to reach consensus otherwise you will only get compliance.

- Provide the necessary support, whether emotional or in terms of resources.

- Provide the tools and training needed to accomplish change.

- Manage diversity.

- Deal with resistance:

- Answer the question: What's in it for me?

- Provide recognition, incentives and benefits.

- Anticipate and address conflicts openly, flexibly and promptly.

- Focus less on things and more on processes.

Communicate, communicate, communicate!

- Share information and facts the leadership sees so that people share the same perspective.

- Help people see the bigger picture.

- Minimize surprises: give people warning about new requirements

- Clarify expectations, standards and requirements.

Plan well:

- Focus on key priorities.

- Divide big changes into manageable steps.

- Minimize amount of time in transition zone.

The director attempted to build a shared philosophy through strategic planning exercises and joint meetings. Although no university policy mandated that a department should appoint a management committee, the BLD and CCDD had management committees. Because of prior histories on both campuses, there was initially a lack of trust in these committees. However, transparency in terms of circulating all minutes and having a standing item on the staff meeting agenda to address issues arising from management committee meetings seemed to overcome this distrust.

Capacity building began in 2004 and formal training was a priority in the budget for 2005. It will continue to be so in 2006 . Training was also organized for the new management committee 
early in 2005. There was a deliberate mechanism for ensuring diversity in terms of race and gender on the management committee and it remained a focus in the activities of the department.

Communication was seen as central from the beginning. Demers, Giroux \& Chreim (2003) agree that communication is crucial in a merger and emphasize the need to send the proper messages to employees. Applebaum et al. (2001, p. 3) state: 'There is a strong need for employees to constantly be on the receiving end of information (Greenhaigh, 1983). Information overload does not apply in these times'. The information should not be contradictory or seem to hide anything and it should give a realistic picture, even when it is bad news. It should also be shared as soon as it is known. Duck (2201, pp. 27-8) also emphasizes the importance of communication:

Communication is always critical but never more so that when you're trying to get others to see and do things differently. So often formal communication focuses on telling people what to do - handing out assignments and required actions - rather than on answering why or explaining how decisions came to be made. People need to understand the thinking that went into decisions.

This was exemplified at a middle management training session at Unisa in April 2005 when a member of management expressed surprise that academic heads of departments could simultaneously complain of lack of communication and of receiving too many communications that required them to do more work. Many people confuse telling/speaking with communication, completely ignoring listening as an essential component. That is why Duck, among others, advises that faceto-face communication is an essential part of a communication plan in addition to e-mails, intranet and print. Giving people the facts also defuses rumours. Not communicating fully does not stop people talking; it merely means that management is not participating in the conversation (Duck, 2001, p. 143).

Although the director did not draw up a communication plan, she did try to implement the principles contained in Table 1. Accurate information was elicited as the basis for facing facts. A regular schedule of visits to the Florida campus (location of former TSA) was arranged, usually two days a week there, so the director could talk to staff, become familiar with people and their feelings and skills. Regular dates were set for management and general departmental meetings. Individual and group interactions were followed up with regular updates on e-mail. A schedule for joint management committee meetings was drawn up with participants to meet alternatively on one of the campuses. A 'merger' item was placed on the agendas of the management and staff meeting agendas. After each portfolio meeting the director summed up the main points and distributed them electronically to the staff. From the beginning of 2005 she sent our regular Monday updates. In addition, although there is no performance management system in place yet, the director scheduled performance consultations three times in 2004 and twice in 2005 to keep in touch with each individual.

In dealing with the 'demerging' of CCDD, the following principles were given priority: take care of the people, reduce uncertainty and provide choice where possible.

Taking care of the people

Applebaum et al. (2001, p. 3) claim that in a merger 'employees are actually the victims of this situation'. There are many natural emotional reactions to change, which can follow a fairly predictable pattern: shock, denial, anger, bargaining, depression, testing and acceptance (Pollack, 2003, p. 16). It is important to legitimize feelings, to make it easy for the person to express feelings and to listen with understanding. It is essential to train managers to deal sympathetically and flexibly with the staff in their care, especially if they tend to be more task-oriented. Managers are considered to be key in staff satisfaction and retention (Buckingham \& Coffman, 1999).

Initially, people were assured of their jobs in the short term; moving to correct functional alignment could ensure medium to long-term security. An advantage of an early line management change for members of CCDD other than the instructional designers was designed to produce a sense of belonging and playing a meaningful role in shaping their future if the new managers created opportunities for involvement. The eventual success of the merger probably depends on how well change, integration and attitudes are managed to give people a sense of belonging to the new departments and the new institution.

Marshall (1999) in his book Building trust at the speed of change: The power of the relationship-based corporation argues that one must build trust first: give people attention and support and communicate all the relevant data honestly. Putting a face on the merger helps to build trust: people must meet their counterparts; leaders and managers must be visible and accessible. This pragmatic approach must be underpinned by values, integrity and ethics to build trust. Marshall sees the most important business challenge as achieving a position 'based on trust, relationships, and collaboration' (1999, p. x/xi). He believes we must 'let go of the past' and accept that people are our most valuable asset and a significant variable in business success. We must 'accept that what people want and need at work is to be trusted, respected, honoured, and acknowledged' (Marshall, 1999, p. xi). He maintains:

A relationship-based corporation is a framework for leading and managing a business that honors the fundamental needs of the individual, builds trust-based relationships, and creates a work environment that can tap into the full potential, intellectual capital, and energy of the workforce, so they are able to produce breakthrough results (Marshall, 1999, p. 5).

He identifies two drivers for 21st century: firstly, 'Rebuilding trust after years of change experiments' (Marshall, 1999, p. 10); secondly, 'The need for speed' (Marshall, 1999, p. 12).

Higher education in South Africa is reeling as a result of massive changes in the system since 1994: demands from SAQA and the Departments of Education and Labour. People are tired of change and now the mergers have been imposed. However, the more people resist and force the university to stay in implementation mode, the greater the stress. We need to move quickly but the speed at which we can reach meaningful determination and fruition depends on how effective the university's leaders and managers are at building trust.

\section{Reducing uncertainty}

If CCDD were to be 'demerged', it would be better to have a single change of line management immediately rather than one change in early 2004 and then another at the beginning of 2005. On this principle, and in consultation with other line managers, recommendations were made to Human Resources through the Vice Principal for the immediate placement of staff in relevant departments that matched their functional expertise. In some cases additional negotiation was undertaken on behalf of staff and the director was present at initial meetings between new line managers and staff where necessary. The director tried to provide a 'safety net' by checking up on feelings and progress in the new environment. She was available on campus every week to share information and uncertainties and to address concerns and fears, as well as to manage the department. It might seem strange to suggest that sharing uncertainties will reduce uncertainty but it does in that it shows that answers are not yet available or that people need to work together to resolve issues. 
Giving choice where possible

Mazaar (1999), in his publication Global Trends 2005, states that choice is important in combating anxiety. Leaders and managers need to empower staff through constructive engagement and create opportunities for people to participate in decision-making. In this process some people had little choice as they had a definite skill such as typesetting. Editors had the option of being placed in Editorial or in Unisa Press. The marketing officer had options within the vice-principal's portfolio, but also in Corporate Communications and Marketing or within Unisa Press. Having a choice gives one a sense of control over one's destiny.

\section{Achieving closure}

Pollack (2003, p. 11) advises: 'Allow expressions of nostalgia and grief for the past; then create excitement about the future'. Applebaum et al. (2001, p. 4) state that 'money should be spent on managing separation as a process' during the merger and then on team building after the merger. The director organized an official closing function for CCDD. The programme included a facilitated session to focus on emotions around closure. After this change management exercise, staff members had lunch and a 'fun' programme to end the day.

\section{Creating a new reality}

From the first meeting held by the two management committees, shortly before the breakaway in May 2004, issues were flagged. The breakaway was followed by a strategic planning session facilitated by two members of Organizational Development and a specialist in strategic planning from the Unisa's Graduate School of Business Leadership. At this session the staff members arrived at a name for the new department that would comprise the instructional designers from the former CCDD and the staff members of the BLD. They did not want to use either 'bureau' or 'centre' and eventually settled on Institute for Curriculum and Learning Development. One of the learning developers had done some research and was able to inform her colleagues that academic units often described themselves as 'institutes' and that suited people's idea of who they are, who their clients are and what they do. A new vision was drafted:

The Institute for Curriculum and Learning Development will lead in creating and sustaining an enabling open distance learning (ODL) environments in Africa. The Institute is committed to excellent and innovative curriculum and learning development, thereby contributing to educational transformation.

This was shortened in 2005 to Transforming teaching and learning in ODL contexts in Africa.

A variety of strategies was selected to fulfil the Institute's purpose: 'competencies, innovation, effectiveness and efficiency'. In the strategic plan they state: 'We shall build our reputation internally through excellent work in curriculum and learning design and development and externally through our papers, publications, contributions to policies, service on committees, work for external clients, etc.' Of course, the department had to align itself to the university's interim goals, as state in the Unisa Business Plan 2004: establish the university as a comprehensive institution; provide quality teaching and learning; provide relevant and quality learner support - which includes 'creating learning development capacity', which is explained in the Unisa Business Plan as:

Define the process of curriculum development, define instructional design, its process and principles, develop internal and client capacity to engage in learning development processes, develop instruments to assist the learning development process, facilitate the process of designing and developing learning process and materials linked to specific quality criteria, introduce relevant, effective and efficient telematic mechanisms, develop relevant integrated courseware; provide quality research; actively engage Unisa's external communities; value the Unisa community; maintain and enhance Unisa's acknowledged academic stature, reputation and reach as a mega university; maintain and enhance efficient and effective service delivery.

The strategic planning session generated a number of objectives that later guided the activity-based budget for 2005: conducting research into ODL, collaborating on curriculum and learning development, undertaking continuing professional learning, assuring quality and developing a departmental culture. However, they were unable to arrive at a definitive structure at the strategic planning meeting and thus had a follow-up session. The resulting structure was flat, with a single line manager, the director. The coordinators and college convenors were to be elected every second year and operate within a matrix structure, not as line managers. Marshall $(1999$, p. 6) points out that in the past organizations were characterized by the 'politics of power and the need to control' and, consequently, hierarchical in structure and culture with no shared vision. The present tendency is to have flat and networked structures and to encourage a sense of ownership. The university's Human Resources department would favour additional line managers under the director because of span of control issues; however, the new Institute was allowed pilot this flat structure for 2005. If the director coped with performance management for over 40 people, the structure would become permanent. The learning developers are highly educated, professional people who work independently across the university in cross-functional teams with academics, editors, graphic designers and so on. They take responsibility for their own work and do not need constant supervision and micro-management. The democratically arrived at structure therefore had a good chance of succeeding. However, the university's performance management system was not yet in place in 2005 so it is difficult to judge the additional burden it would put on the director as indications are that there would be four performance management meetings a year.

Task teams were initiated to address the issues that were flagged along the way; for instance, writing up the key performance areas (KPAs). The teams were composed on the principle of each having equal numbers of BLD and instructional designers from CCDD to ensure that the minority CCDD voice was not swamped (the former CCDD members comprise about $25 \%$ of the Institute). This arrangement meant that instructional designers sat on twice as many teams, though, but it was preferable to silencing them through under-representation.

During 2005 additional workshops took place around curriculum development, instructional design and quality assurance of materials, among other things. These workshops were useful in moving staff members towards a common understanding of the core business of the Institute.

The director wanted learning developers and instructional designers to work together on new projects to observe each other's methods and move closer to consensus about how to conduct their business. The dominant methodology was supposed to be that of the campus at which the lecturer was located. This collaboration started to reveal interesting learning points for the new comprehensive institution related to programmes. The process also uncovered further misalignments between structures and functions: the failure to ascertain the functions of departments across the two campuses in the 'as is' analysis and to align them accurately has led to tensions. Unfortunately, having two people working on a project and observing the methodology of the host campus did not achieve its goal. Many of the projects 
were on the Florida campus but the old BLD methodology seemed to take over for a variety of reasons so mutual learning did not occur and methodologies and paradigms have not merged.

\section{REFLECTION AND DISCUSSION}

The following quotation from Anderson and Anderson (2004, p. 1) struck such a chord that it is used to structure much of the reflection on the change management process below:

Transforming is a very uncertain and unpredictable process that requires a new leadership approach: 1) the outcome is unknown at the start and must be figured out as you proceed; 2) this 'figuring it out' process requires constant course correction; 3) this journey is only semi-controllable and largely erratic; and, 4) given the magnitude of uncertainty, people get mentally and emotionally triggered with feelings of fear, anger, and confusion.

The statement epitomizes the experiences ICLD has had since the merger.

The outcome is unknown at the start and must be figured out as you proceed

Another comment by Anderson and Anderson $(2004$, p. 2) - 'Tell the truth about the change: what is happening and what is known. Of equal importance, share what is NOT happening and is NOT known about the change.' - exemplifies how the Institute had to operate. The director often had to say 'Ask your questions but we won't always have the answers'. A drawback is that rumours arise in this situation and it is of the utmost importance to defuse them immediately. The different competencies of the new department were listed in the mission and menu of services in the strategic plan in 2004 and in the KPA document, but what looked like consensus on the issues might just have been compliance. Despite opportunities and training it is still not clear that everyone will become equally competent in all areas either because they are reluctant to move out of their comfort zones or because they are genuinely incapable of acquiring the competencies.

This 'figuring it out' process requires constant course correction They started with an imprecise understanding of the environment on both campuses so they made missteps and had to correct their course. For example, they included the project managers in the new Institute but later separated them out into a Project Management Office located in the office of the Executive Director in the Vice Principal's portfolio.

This journey is only semi-controllable and largely erratic Inevitably, when one is part of a larger system, one has a limited area of control. Because the merger involved systemic change, the impact of changes in one area affected planning and operations in others. Or the Institute would proceed cautiously but quickly and the system had not yet developed to accommodate their plans; for example, the placement procedures had not been determined for placements below the level of director but they wanted to facilitate one line management change. They decided to have a separate Institute for Curriculum and Learning Development and Project Management Office for 2005 and drew up different budgets for both new departments but the new structures had not yet been approved so the budgets had to be reintegrated.

Given the magnitude of uncertainty, people get mentally and emotionally triggered with feelings of fear, anger, and confusion Initially fear and anger were most noticeable among the CCDD members. As the merger process developed after the breakaway there was increasing confusion and anger on the part of the BLD staff as it became clear that they would have to work with their new colleagues to create a new vision and it would not be business as usual. Even when the Institute achieved a small success by creating an area of certainty, the larger uncertainty around the future of the campuses remained a threat and potentially undermined these efforts. In this situation it was important for the manager to be there and listen again and renegotiate; in other words, to provide a 'safety net'. The university had a change management team with a representative in the Learner Support portfolio to which BLD and CCDD were allocated but no structured, systematic interventions or counselling were provided on an individual or group level.

Considering the magnitude of the change for CCDD and the displacement of its director, the staff members behaved with restraint, courtesy and cooperation. However, there was evidence of demotivation and stress. Some people in BLD and CCDD indicated that they would be willing to take a voluntary package if offered. There was one resignation from BLD in 2004 (not merger related) and four from CCDD (only one instructional designer, clearly merger related). Leaders and managers have to be aware of the human side of the merger all the time and address uncertainties through the strategies discussed in this article. They have to do the best they can for their staff, serve the university's and department's core business and keep the end in the mind: a single, comprehensive dedicated distance education institution operating effectively and efficiently to serve the needs of its students, its employees, society and the broader enterprise of generating and distributing new knowledge.

\section{CONCLUSIONS}

The following criteria could be used to evaluate the impact of the deliberate use of change management principles in the new ICLD: staff morale; staff retention; levels of absenteeism; diversity profile of management committee; staff satisfaction with director's performance; staff satisfaction with communication; increased levels of competence in core business; planning processes and frameworks, and where the Institute is in the merger process.

Staff morale seems fairly high most of the time: levels of absenteeism due to ill health or taking unofficial time off work are not noticeable judging by sick leave forms and availability of staff; after the initial staff losses in CCDD, only one of them an instructional designer, no other staff members have resigned, in contrast to rather attrition in some other sections of the university. The Institute Management Committee (IMC) is perhaps too big but the aim is participatory management. It includes the director, her PA, the office manager, the project service manager, four elected coordinators and five elected college convenors. There is thus a significant level of participation in management and planning for the department. Of the thirteen people, six are women, one black; seven are men, five black. The gender and race balance is thus equitable.

A survey was conducted on the director's performance at the end of 2004, which gives data to evaluate some of the change management strategies and the director's perceptions that progress has been made. Staff satisfaction averaged 3,52 out of four on 30 items, dealing with planning, organizing, leading and monitoring, with the lowest score 3,09. Clearly there was room for improvement but this was not a bad rating. One can relate the qualitative comments to one of the original propositions, that 'relationship building and participation would lead to greater buy-in and facilitate the merger by building trust'. Four comments show that there are perceptions that the strategies have not completely succeeded: 'Always behave transparently and make the information that led to decisions visible', 'Build faith/ trust', 'Give fair and equal treatment to all staff members regardless of location, race or history' and 'Have a stronger democratic and more inclusive 
approach'. There was also a perception in the evaluation that the director had not succeeded in dealing effectively with affective issues. For instance, one comment stated: 'Consider all facts and personalities before making decisions. Take the feelings and sensitivities/ interpersonal intelligence of staff members into account', while another urged 'Be more peopleoriented, listen to problems, be more approachable' and a third enjoined her to 'Recognize trends of unhappiness and disagreement in the department and react positively and proactively', a very tall order. A second proposition stated that 'effective communication was essential'. However, the evalutation revealed that another area in which the director needed to improve was in the area of interpersonal communication and giving recognition, as the following comments show: 'Talk more to staff about their performance and progress', 'Give more regular feedback on individual performance to the person', 'Spend more time with ordinary learning developers outside meetings' and 'Give frank feedback on strengths and limitations in confidence'.

Quality circle research into the relationship between well-being and communication in mid 2005 resulted in a series of focus group interviews, another source of data. Questions were specifically designed with an appreciative enquiry slant, asking what was working, but nonetheless perceptions of problems around communication, some personal, some systemic, were revealed. The observations were not about the director but about general communication in the Institute. It was felt that people do not listen. The director had actually identified this issue during a team meeting earlier in the year and had tried to improve the understanding of communication in the whole department by sending out a short article on the subject. Another problem identified was that communication is not two way. While the director often sends out information, there is not enough time and space for discussion. People also put different interpretations on communication. The director had also identified earlier in the year that people tend to lash out instead of checking for understanding. That dysfunctional type of communication was also addressed in the short article. The data from the focus group interviews are still being analysed and interpreted and will therefore not be addressed in any further detail.

Positive feedback comes from individual anecdotal evidence. The capacity building in 2005 has resulted in increased competence in core business including curriculum development, instructional design, planning of assessment, outcomes-based education, evaluation of material, using e-learning and writing for publication. Staff members have expressed their feelings of greater confidence as a result of the training.

The first strategic and action planning cycle in 2004 laid a firm foundation for the 2005 plan for 2006. The IMC monitors and evaluates the action plan for the year every three months to see if objectives are being achieved. The director, who was a newcomer to departmental management in 2004, has also learnt how to use the planning as a framework for an activity based budget.

The most honest conclusion is that the change management strategy has succeeded to some extent but that it could have been executed more efficiently and effectively. Duck has two pertinent comments:

It is wishful thinking to believe that plunging into action will solve underlying conflicts and eradicate lingering doubts. For example, don't assume that once a person knows he or she has a job, and what it is, he will be fully engaged and loyal to the new organization' (2001, p. 156) and 'intention does not equal effect. A person may intend one thing and yet cause a totally different response in someone else' (2001, p. 181).

The director has had experience of communication being misinterpreted; not only because of different cultures between former departments but as a result of individual cultural differences including language, gender and race. Also, some actions are well meant, such as allowing staff members a great deal of autonomy as a demonstration confidence, but not they are always perceived that way: some people believe that guidelines need to be in place. Once again this is a cultural issue based on the degree of independence, structure and scope previously experienced at the former institutions. Different cultures are one of the most difficult issues to resolve along with differences in beliefs about teaching and learning in ODL contexts and a commitment to a transformative approach.

The director has a strong suspicion that some people in the Institute may be in premature 'determination' before important cultural, operational and philosophical issues have been resolved:

In this phase, people ask themselves the hard questions about their current place and their future within the organization. Can I do this job? Do I want to do this job? Do I trust our leader? Do I like where the company is heading? How does my new life compare to my old one? What is my future here? Am I being adequately compensated, rewarded, and recognized for the seemingly endless pain and hassle we have been through - and may still have to go through? Would it be easier/ faster/ smarter to start over somewhere else? Would I be better off in a totally different situation? As the reality of the changes sinks in, people gradually (or sometimes, suddenly) understand that their working lives have been profoundly altered and things will not return to 'normal' or to the way they 'used to be' (Duck, 2001, pp. 197-8).

Others are operating within former paradigms as if nothing changed in the merger; the difficulty with merging or recreating beliefs and practices mentioned earlier. The distance between the campuses continues to make it particularly difficult to develop new, common understandings and practices; conversely, it allows people (on both campuses) to cling to old practices without being too visible.

The change management strategy has kept staff informed of progress in the merger at the macro level through constant communication; the focus on participation and training has increased capacity and kept staff turnover low. The enhanced capacity has added greater value to the Institute's services to the academics and in many cases bolstered confidence, flexibility and morale. Where teams are working across campuses, after some initial storming, there is exciting synergy. The director continues to monitor progress and plans to build further capacity in 2006.

The article started by asking two questions: What impact would the implementation of change management principles and practices have? How could it help to meet current demands while preparing for long term strategic goals - the university's and the department's? The implementation of change management principles worked to a great degree in the ICLD merger, reducing stress, absenteeism, etc. and increasing trust but change management principles and practices need to be systemic in a merger to have the most impact. Mergers, it is clear, place an almost impossible strain on all concerned but the stress can be alleviated through careful planning and an excellent communication plan. Putting principles first, such as caring for employees, helps to ensure that the merger does not falter through lack of cooperation. Attention to attitude and culture is essential. Working towards a win-win situation also pays dividends. Training line managers with change management skills would pay off. It is the preparation phase that ensures success as well as perserverance in the implementation phase. Spending time on human issues to meet current demands might slow the process somewhat initially but lays a solid foundation to achieve future strategic goals whether at departmental or institutional level. 


\section{REFERENCES}

Applebaum, S.H., Gandell, J., Shapiro, B.T., Belisle, P. \& Hoeven, E. (2001). Anatomy of a merger: behavior of organizational factors and processes throughout the pre- during- poststages (part 2). Management decision, 38 (10), 1-11.

Anderson, L.A. \& Anderson, D. (2004). How to be a strong leader in the face of uncertainty. Retrieved July 13, 2004 from http://www.workinfo.com/newsletter.

Brousseau, K.R. (1989). Navigating the merger transition. Journal of organizational change management, 2 (1), 72-78.

Buckingham, M. \& Coffman, C. (1999). First, break all the rules: What the world's greatest managers do differently. London: Free Press.

Collins, J. (2001). Good to great: Why some companies make the leap and others don't. New York: HarperBusiness.

Demers, C., Giroux, N. \& Chreim, S. (2003). Merger and acquisition announcements as corporate wedding narratives. Journal of organisational change, 16 (2), 223-242.

Duck, J.D. (2001). The change monster: The human forces that fuel or foil corporate transformation and change. New York: Three Rivers Press.
Hay, R., Lowe, D., Gibb, D. \& Anderson, B. (2002). Breaking the mould: Deakin University, the first twenty-five years. Geelong: Deakin University.

Marshall, E.M. (1999). Building trust at the speed of change: The power of the relationship-based corporation. New York: Amacom.

Mazaar, M.J. (1999). Global trends 2005. New York: Palgrave.

Mergers - The Cisco System, Secrets of US Computer Giant's Success. (2002). Strategic direction, 20 (7), 25-27.

Ottoway, R.N. (1983). The change agent: A taxonomy in relation to the change process. Human relations, 36 (4), 361-392.

Pollack, L. (2003). Leading organizational change. Seminar: The Pennsylvania State University, Office of Human Resources.

South Africa. (2001). Department of Education. National plan for higher education. Pretoria. Retrieved on September 30, 2005 from http://education.pwv.gov.za/content/documents/ 706.pdf.

Tellis, W. (1997). Application of a case study methodology. The qualitative report, 3 (3). Retrieved June 21, 2005 from http://www.nova.edu/ssss/QR/QR3-3/tellis2.html. 